Sharif University of Technology
Scientia Iranica
SCIENTIA

Invited/Review Article

\title{
Grid modernization for enhancing the resilience, reliability, economics, sustainability, and security of electricity grid in an uncertain environment
}

\author{
M. Shahidehpour ${ }^{a, b}$ and M. Fotuhi-Friuzabad ${ }^{a, *}$ \\ a. Center of Excellence in Power System Control and Management, Department of Electrical Engineering, Sharif University of \\ Technology, Tehran, P.O. Box 11365-11155, Iran. \\ b. Department of Electrical and Computer Engineering (ECE), Galvin Center for Electricity Innovation, Illinois Institute of \\ Technology (IIT), Chicago, IL, USA.
}

Received 4 May 2016; accepted 19 November 2016

\author{
KEYWORDS \\ Grid modernization; \\ Smart grid; \\ Reliability; \\ Rresiliency; \\ Security; \\ Economics; \\ Distributed supply \\ technology.
}

\begin{abstract}
This paper reviews the merits of modernizing the power grid and discusses the way electric utilities in various countries are directing their practices toward offering enhanced sustainability, reliability, resilience, security, and economics to their respective consumers. The modernization of the electricity grid, which has evolved as the brainchild of electricity restructuring, has been made all the more urgent by the virtually pervasive dependence of modern lives on a reliable, clean, and secure supply of affordable electricity. The electric utility industry restructuring, which has staged many institutional, regulatory, and business models, has enabled the modern electricity grid to take full advantage of a range of available energy sources and modern technologies pertaining to prosumers and transactive energy, renewable supply, storage, energy efficiency, climate change and carbon capture, electrification of the transportation industry, microgrids and resilience, and large fossil units that have helped the electric utility industry meet its global objectives. Understanding the dynamics of grid modernization, which can offer a clear appreciation for the use of innovation in electric power systems, and the impact that grid modernization will have on individual lives, is among the issues which will be discussed in this paper.

(C) 2016 Sharif University of Technology. All rights reserved.
\end{abstract}

\section{Historical perspective}

Electricity is central to the well-being of any nation. The transitions from wood to coal to oil and the rise of electric power were accompanied by sweeping technological, sociological, and economic changes in the 20th century. More concentrated and large energy sources enabled the industrial revolution and facilitated mass migrations to cities of those who were seeking prosperous job opportunities and more glam-

*. Corresponding author. Tel.: +98 2166165921 E-mail addresses: ms@iit.edu (M. Shahidehpour); Fotuhi@shairf.edu (M. Fotuhi-Friuzabad) orous styles of living in metropolitan areas across the globe. Electricity allowed the rise of tall buildings once elevators, which were equipped with electric motors, were invented, introduced electric appliances at home, and automated many daily tasks at workplace for increasing productivity and enabling the digitization of the world [1].

In 1882, Thomas Edison started the Pearl Street Station in New York, which was the world's first central power plant and operated as the world's first microgrid (cogeneration plant). While the steam engines provided grid electricity to neighboring homes and businesses, Edison made use of the thermal byproduct by distributing steam to local manufacturers and warming 
nearby buildings on the same Manhattan block. The isolated large power systems were established at the turn of the century, which revolutionized manufacturing businesses and created industrialized societies across the globe. In the 1930s, isolated power systems melded into interconnected systems. In the $1950 \mathrm{~s}$ and 1960 s, isolated systems were converted to large regional pools. Using power pools, bulk power was generated at centralized power plants and delivered over long distances. With economies of scale, prices declined and demands increased.

Today, an electric utility provides a commodity service that is considered essential in many respects to the general public. The electric utility service has also been deemed by several governments as a regulated operation because the service is a vital public interest. Traditionally, electric utility has offered affordable services using a single supplier in a defined franchise territory because of the high cost of distribution infrastructure. The cost of generating power continued to decline as power utilities built ever-larger power plants, which increased efficiency and reduced production costs. Increased electric demand required even larger plants, which reduced costs further and increased the rate base. This era of development was historically a win-win for everyone. Consumers had abundant, lowcost power at declining rates, increased electrification, and economic growth. Centralized electric utilities were also granted certain monopoly rights to prevent price gouging and encourage widespread access for selling electricity to retail consumers at regulated prices in their specific service areas.

Key features of a regulated model for electric utilities included the following:

- Electric utilities generated and dispatched economic power, served consumer demand, and maintained reliability by large and centralized plants in their service territory;

- Electric utility used regional transmission lines, which were regulated by governments for wholesale transactions;

- Major electric utilities imported power as deemed necessary and exported surplus power to meet adjacent utility demands, and managed the economics and the reliability of power transactions using sophisticated Energy Management System (EMS) technologies installed in local dispatch control centers [2].

\subsection{Oil crisis of the 1970s}

The 1970 OPEC oil crises changed the golden era in a flash. Rapid increases in fuel costs for operating fossil-based power plants in many parts of the world translated into large increases in retail power prices. The sustained increases in oil prices and unstable fuel supplies in international markets led many electric utilities to construct new power plants that relied on domestic fuel (e.g., hydro, coal, and uranium). These power plants costed much more to build than the traditional oil or natural gas-fired plants. Consequently, the fixed costs of electric utility operations increased, which further increased retail electricity prices globally.

The higher electricity prices resulted in a public outcry, which ultimately increased the regulatory oversight by governments for stabilizing the electricity prices. The consumer resistance to higher rates of electricity and poor economy resulted from higher fuel prices, ultimately culminating in a decline in electricity consumption. In this era of decline, electric utilities ended up with large stranded assets as they operated too many power plants and/or plants that were too costly. In the mid-1980s, the regulated electricity situation appeared to be out of control in the western hemisphere with electric utilities requesting higher regulated rates and several electric utility companies on the verge of bankruptcy. In the early 1990s, the State of California had some of the highest electric rates in the United States and was looking for ways to boost its economy in the aftermath of high cost of electricity for conducting business. In essence, economic development was slowed down where electricity rates were high and manufacturing firms were flocking to low-cost states.

It was becoming apparent that regulatory approaches for the electric utility industry in the United States were not working. In this regulatory environment where electricity prices were deemed to be high, the potential implications of introducing a more comprehensive electricity demand response, deployment of distributed generation and renewable energy at increasing rates, introduction of new fossil-based technologies for power generation, and growing opportunities for introducing Smart Grid technologies and consumer interactions with the power distribution grid were further questioning the legitimacy of regulatory boundaries on electricity generation and delivery that had evolved over the past century.

\subsection{Electricity utility restructuring in the $1990 \mathrm{~s}$}

The launching of several technological trends paved the way for electric utility restructuring in the western hemisphere. The first approach, defined as the Integrated Resource Planning (IRP), was the introduction of energy efficiency in both the production and the consumption of electricity, which limited the peak load supplied by electric utilities. As a result of IRP, government regulators required electric utilities to evaluate energy conservation and implement load management technologies rather than building new power plants for managing utility loads. IRP was successful in keeping retail rates in check, although 
regulated rates were still considered to be relatively high.

Rising fuel prices also hit the transportation industry very hard. In response, engine manufacturers designed more fuel-efficient motors and jet engines that were later used as peaking power plants in the electric utility industry. The combined-cycle natural gas power plants based on the new jet turbines were smaller in size, had much higher energy efficiency, and offered lower production costs. Thus, the notion of "the bigger the better", which was followed in previous decades by electric utility industry planners for installing large generating units, was put into questions.

The higher electric utility demand for natural gas could not be satisfied at 1970 levels of production owing to peculiarities in the natural gas industry regulation. Solving the natural gas problem led to the restructuring of the natural gas industry in the United States by unleashing market forces to free up natural gas for electricity generation, which paved the way for the electric utility industry restructuring in the 1990s.

The electric utility restructuring path involved existing electric utilities selling off their power generators and the operation of transmission lines was taken over by third-party grid operators (i.e., Independent System Operator) who operated the transmission assets as a single system that would serve regional competitive wholesale power markets. Figure 1 shows a conceptual comparison of vertically integrated and

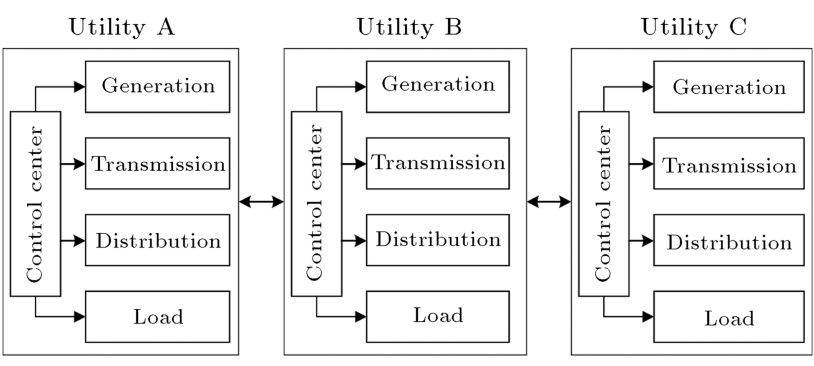

(a)

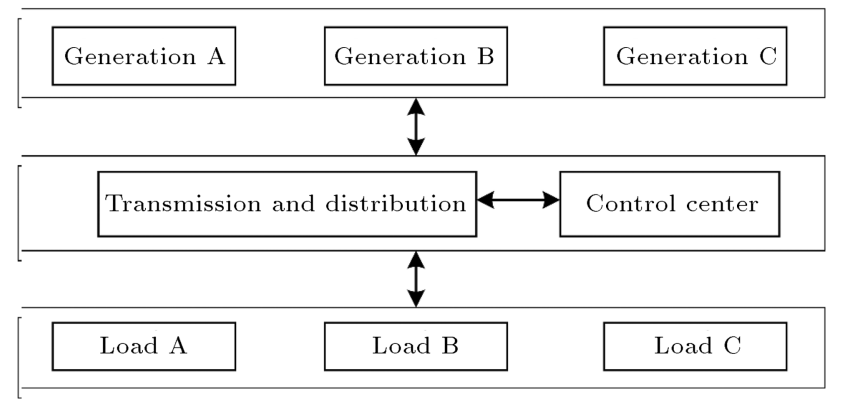

(b)

Figure 1. Structure of vertically integrated and restructured electric power systems: (a) Structure of vertically integrated electric power system; and (b) structures of unbundled and restructured electric power systems. unbundled/restructured electric power systems.

In the traditional vertical system, although a utility might purchase power from neighboring electric utilities, it was primarily responsible for its own generation, transmission, and distribution of power to retail consumers in its service territory. In the horizontally restructured power system, however, generation and transmission systems were unbundled and consumers were free to purchase from any suppliers on the grid. In the restructured electric utility operation, transmission scheduling was conducted by grid operators (ISOs) and power purchases were done collectively via market mechanisms like the power exchange (PX).

Electric utility industry restructuring, which resulted in the growth of independent power producers and competitive wholesale electricity markets, introduced many new institutional, regulatory, and business models. The restructuring models effectively demonstrated that the traditional practice of providing utility consumers with electricity from a vertical monopoly provider was not as economical and giving retail consumers the opportunity to choose their power supplier stimulated electricity markets to reduce power costs and increase power products and services. The restructured electric utility industry promoted higher quality for delivering energy services with lower electricity prices, which resulted in improving the productivity in various geographic regions, protecting the environment, and ensuring the national security.

Restructuring has exacerbated the interdependency of electric utility with other infrastructures including water, natural gas, telecommunications, transportation, and emergency response systems. The historical perspectives have demonstrated that the supply of oil and natural gas in the global arena is often intertwined with political conflicts, which have made it more cumbersome to deliver the fuel supply to generating plants. International conflicts have also caused overhead transmission lines to be very vulnerable to physical attacks. The vulnerability of transmission corridors in certain parts of the world has rendered it impractical to deliver large sums of fossil-fuel based power generation over long-distances. The applications of distributed power systems and local microgrids may remedy some of these emerging problems in restructured power system.

\section{Grid modernization in the aftermath of electricity restructuring}

The restructuring of the electricity grid allowed market participants to take full advantage of a range of available energy sources and technologies (e.g., energy efficiency, renewable energy, energy storage, carbon capture, electric vehicles, and other distributed technologies as well as large nuclear, natural gas, and 
hydropower generation) that helped electric utility industry meet its global reliability, resilience, security, and economic goals. A revolutionary application of information and communication technology (referred to as Smart Grid) changed the nature of power generation, transmission, distribution, operation, and control in the aftermath of electricity restructuring. Smart Grid is designed to monitor, protect, and automatically optimize the operation of interconnected power systems and their elements, starting from central generation and distributed generation plants, transmission and distribution systems, commercial and industrial users, to consumer devices, thermostats, and appliances. Smart Grid includes a host of new and redesigned applications, such as phasor measurement units and advanced metering infrastructure, that utilize advanced information and communication technologies to provide substantial benefits to participants represented by increased economics, reliability, security, and resiliency of the power grid [3].

The modernization of the electricity grid stemming from Smart Grid implementations is made all the more urgent by the virtually pervasive dependence of modern life on a reliable and secure supply of affordable electricity. Without electricity, navigation, telecommunication, financial system, healthcare, emergency response, and the Internet as well as all that depend on them become unreliable. However, a large electricity infrastructure is often challenged by increasing vulnerability to severe weather because of climate change, cyber and physical threats, and growing consumer-level interactions through Smart Grid. The threats to the grid-ranging from malicious attacks on transmission lines and substations to more flooding, faster sealevel rise, and increasingly powerful storms from global climate change-have grown steadily as society's dependence on the electricity grid has increased. In addition, consumer applications and digital technology have altered society expectations of what the electricity grid should offer. Once satisfied with a simple arrangement where electric utilities provided services and consumers bought power on fixed rates, individual consumers and companies are increasingly interested in controlling the production and delivery of electricity, and the enabling Smart Grid technology has become available to allow such consumer provisions. These trends, coupled with flat or declining electricity demand (resulting from a softening economy as well as the introduction of higher energy efficiency and demand response), have dramatically altered electricity business models in which local and distributed generation and storage are more appropriately valued and utilized [4].

A positive resolution of grid modernization is that it can mitigate growing vulnerabilities of the power grid to cyber-physical and climate change threats in the aftermath of electricity restructuring. The grid modernization offers a broader perspective on energy security (which has previously focused mostly on international oil and natural gas supply security). The broader perspective includes not only the grid reliability, which pertains to the ability of the electricity grid to withstand incipient shocks in supply and delivery systems (including international energy price hikes and political conflicts, thunderstorms, and cyber-attacks), but also a quick recovery from any extreme shocks (such as major natural storms) with devastating effects on the resilience of power systems.

Grid modernization supports a secure communication network-its information backbone-that will enable communication among power grid components, from generation to consumer level, and protect the power system from cyber intrusions. The communication network will support the ability of a modern electricity grid to monitor and control time-sensitive grid operations, including the frequency and voltage regulation and optimal dispatch of constrained generation, analyze and diagnose threats to grid operations, fortify resilience by providing feedback that enables self-healing of the grid after major disturbances, and evaluate massive data provided by sensors (such as phasor measurement units) that enable the modern grid to maximize its overall capacity in a dynamic power system operation [5].

\subsection{Impact of increased variability on grid modernization}

Grid modernization introduces innovative technologies and services to power systems at an unprecedented rate, but also injects uncertainty into the electricity grid operations, traditional regulatory structures, and utility business models. For instance, the variability of integrated renewable sources of electricity is a utility challenge, which has been intensified in the aftermath of restructuring. Modernizing the grid will introduce challenges that need to be addressed as a result of operating an electricity grid with additional variable elements. When an electric utility system has a large share of variable resources, fossil-fuel based power sources must be more flexible for handling variable weather patterns that impact the availability of renewable power sources. The greater the percentage of variable renewables in a utility system, the greater the flexibility needed by the fossil-fuel based generating system [6].

In addition to providing a mechanism for mitigating the adverse consequences of variable generation, grid modernization will enable electric distribution utilities to actively control consumer-owned distributed generation units to improve the efficiency, reliability, and overall performance of the electric distribution system. The need to deal with increasing penetration of distributed generation units, coupled with the need to 
reduce electrical losses and improve overall efficiency, has resulted in the growth of advanced distribution model-driven volt/var optimization systems. Many electric utilities are currently demonstrating volt/var optimization on distribution systems as a key part of their grid modernization strategy. Distributed generation units equipped with smart inverters play a role in managing the volt/var optimization along the feeder as well as supplying reactive power to improve the power factor and reduce electrical losses [7].

\subsection{Role of renewable energy integration in grid modernization}

A shift toward wind and solar is a shift away from the traditional fossil based power that was readily available whenever it was needed. The challenge of variability increases the cost of adding renewable electricity to a power grid. The power equipment will run at full utilization more often at higher quality sites, producing more power for the same investment. Any reduction in power generation from fossil fuels, when variable sources are available, is good for reducing greenhouse gas emissions, but means that the fossil-fuel plants will face a more difficult task of covering their fixed costs. In addition, some fossil-fuel plants are less efficient when they are cycled up and down, adding costs to the power system as a whole.

Accounting for these system-wide costs of integrating variable renewable resources is a subject that will gain greater attention as the share of renewables grows. The utility-scale electricity storage is a potential technological solution to the challenge of variability, but such a solution has so far proved elusive. Large hydropower dams provide some element of flexibility and energy storage, and pumped-hydro storage units are designed to pump water into a reservoir during times of low demand to release for power generation at high demand times. However, these systems are very site-specific and expensive. The use of storage will reduce the reliance on the back up grid power as we increase the grid integration of wind and solar PV. However, the large-scale battery industry has a long way to go, though the payoff would be enormous. It should be noted, however, that storage will also benefit conventional electric power generation by reducing the need for fossil-fuel based power plants that only run at times of peak load [8].

The potential for reverse power flow on distribution feeders caused by a high penetration of distributed generation units poses significant challenges to existing voltage-regulating mechanisms. Sudden drop-off of solar power installed at the consumer site due to passing clouds and of wind power due to lower winds could result in a significant increase in fossil-fuel based power drawn from the electric utility and a resulting substation voltage reduction that must be countered by voltage regulators and capacitor banks. The sudden return of wind and solar power generators may produce high-voltage conditions at substations that must be similarly countered. Distributed generation units coupled with energy storage and advanced control systems will also enable electric distribution utilities to establish islanded microgrids for resiliency that can continue to serve consumers in the local community even when the microgrid becomes separated from the main grid and/or a widespread power outage occurs.

\subsection{Role of grid modernization in cleaning the environment}

The traditional advances in electricity generation generally focused on enhancing steady, reliable, yet large and often polluting sources of energy. The power grid infrastructure is shaped not only by the mix of energy supply technologies and end-use patterns, but also by the characteristics of the environment where the infrastructure operates with greater vulnerabilities to earthquakes, extreme temperatures, hurricanes, drought, wildfires, intense precipitation, and flooding. Sea-level rise, thawing permafrost, and increases in weather extremes have already affected the grid infrastructure in many global regions. Grid modernization takes into account the serious need to limit the electric utility infrastructure's adverse impacts on the environment. The regional grid modernization for mitigating unfavorable grid effects can include the establishment of greenhouse gas emission standards, higher integration of renewable and cleaner electricity generation technologies, use of electric vehicles, continuing improvements in end-use efficiency, and allowing the energy consumption embedded in Smart Grid [9].

\subsection{Role of energy efficiency initiatives in grid modernization}

Efficiency is a means of dealing with three major goals of grid modernization-inexpensive, secure, and low-carbon supply of energy. Ironically, the most secure and low-carbon form of energy utilization (i.e., maximizing the use of energy efficiency) is not to use energy at all. Technological innovation and Smart Grid applications allow consumers and businesses to do more with less in terms of their energy use. Policy tools are being developed to help overcome barriers to investment on energy efficiency and market development for integrating energy efficiency. Variable energy market prices and carbon taxes make efficiency investments more financially attractive to end users.

Grid modernization can also contribute considerably to energy efficiency. Using grid modernization technologies, the overall level and the composition of energy supply is optimized by more efficient use of energy alternatives and transitions toward universally adopted energy conversion. Advances in information 
and communication technologies and data management can take this revolution even further by utilizing the information on the behavior and desired lifestyles of millions of empowered consumers. Smart Grid applications and the use of computing architecture towards cognitive systems can help consumers and electric utilities better understand electricity demand patterns and automate the options for demand response to maximize energy efficiency.

In more practical terms, energy subsidy can make investments on energy efficiency and renewable energy more attractive. Energy subsidies on fossil fuels are commonly applied, particularly in developing countries, to reduce consumer electricity bills. Alternatively, redirecting subsidies towards low-carbon forms of energy use can help promote grid modernization. Also, subsidizing a lower level of electricity consumption will guarantee that the subsidy goes into the pockets of low-income citizens [10].

\subsection{Role of customer communication devices in grid modernization}

The evolving role of the modern-day electricity consumer is transforming into a more dynamic and transactive role in which consumers are both suppliers of responsive demand and producers of distributed power. As suppliers of flexible demand, consumers can provide capacity resources to the power grid that help maintain the grid reliability at affordable prices, reduce greenhouse gas emission, increase resilience, and forestall infrastructure investments.

The residential and commercial building applications of Smart Grid could include packages of pricing, in-home displays, smart appliances, and information portals that would reduce building energy demand. Also, well-designed control systems for consumer applications can increase the building efficiency. Speeding the adoption and accrual of potential consumer benefits will require the coordination of interoperability energy devices and business models that enable such benefits to be widely implemented. An open standard for the interoperability of energy devices would be analogous to the voluntary industry standard developed for USB in the mid-1990s, which allowed simple plug-and-play between peripheral devices. The USB interoperability greatly expanded the usability and types of personal electronic devices among consumers.

Capturing these benefits in the utility industry requires building communication networks, allowing components to interoperate and respond to a facilitywide control. The applications of new information technology enable new behaviors, market mechanisms, and monitoring and operating procedures. However, lack of regulatory standards is impeding the grid modernization for a full utilization of information technology that can enhance the grid reliability and consumer efficiency. Lack of comprehensive communication and data standards can hinder consumer values and inhibit the adoption of Smart Grid technologies and control strategies for lowering the deployment cost at consumer sites.

Furthermore, it is perceived that, while the reliability and efficiency of the utility system can be improved in the long run by consumer participation, the information based grid modernization alternatives could pose a threat to the status quo in the utility industry and potentially present significant and unintended consequences and ambiguous benefits for electric utilities. As a consequence, there is a general caution in the utility industry associated with the wide-scale deployment of new information technology infrastructures and Smart Grid devices, which can only be dealt with through regulatory mandates in various countries.

\subsection{Role of $R \& D$ in grid modernization}

Grid modernization will aid planning activities in the electric utility industry that can capture greater endto-end efficiencies and enhance the power industry's ability to reach its economic, security, and environmental goals as discussed below:

Economic competitiveness: Modern grid should enable new architectures that can stimulate energy efficiency, economic transactions, and new consumer services. The pertinent research on the modernization of energy infrastructure should consider the design of a utility grid which, under fair and transparent market conditions, can produce products and services that are attractive to international markets while simultaneously maintaining and expanding jobs and higher wages extensively.

Environmental responsibility: The pertinent research on energy infrastructure should develop and manage an environmentally responsible operation, taking into consideration the imperatives of climate change and the societal costs and benefits of reducing or avoiding pollution and land-use impacts on a lifecycle basis. The research on expanding the environmental responsibility should minimize the environmental footprint of energy use while enabling better environmental performance more broadly for utility systems. It is also important for environmental studies to consider policies that promote equity and avoid disproportionate societal impacts on any particular population.

Energy security: The pertinent research on grid modernization should minimize vulnerabilities resulting from disruptions to energy infrastructure and mitigate impacts of such disruptions, including socioeconomic impacts. If disrupted by any extreme events 
(e.g., hurricane, flood, earthquake, and cyber and physical attacks), the modern grid should be equipped properly to recover quickly. Energy security should support overall national security and encompass a collective approach to the security of the country's trading partners [11].

\section{Grid modernization technologies}

Key technologies and capabilities representing the foundation for comprehensive grid modernization include:

Wide-area monitoring and visualization. In a modern grid, integrated advanced sensors and robust communication systems provide greater visibility to the power system state and enhance the situational awareness for identifying the critical spots in the power system hierarchy. Situational awareness means understanding the current operation environment and being able to respond effectively and accurately to the anticipated future problems. In a more complex and modern grid environment, utility operators would need to know with greater precision than ever before how close the system is to the edge and how quickly they are moving in any particular direction. Several electric utilities over the past decade have already deployed synchrophasor technology to enhance the power system visibility and increased their use of synchrophasor data for on-line and off-line monitoring applications. Numerous applications of phasor measurement unit data include oscillation monitoring, event location, and extra-high voltage state evaluation. Power system oscillations cause equipment damage, reduced stability margins, and other operating problems. Event location expedites outage restoration by quickly identifying probable outages.

Modern grid communication technologies. A variety of communications technologies-home area networks, neighborhood area networks, and wide area networks-will be deployed in a modern grid to enhance the utility grid operational performance and efficiency and to provide information and control data to Smart Grid consumers. In the near term, communications networks would typically be characterized as singlepurpose, while the interfacing of data and systems would be handled on an individual basis. It is envisioned that, in the longer term as we expand the steps for grid modernization, communications networks will begin to converge on a larger scale and become unified for utility applications.

Modern grid control technologies. In a modern utility grid, human operators use system-wide dynamic control data for real and reactive power management. Advanced control devices and automated response strategies allow utility operators to manage an environment which includes consumer participation, evolving demand response, and variable generation resources. The ability to harness storage capacity in a power system with variable resources provides important shockabsorber capability, complements variable generation, and provides better tools to utility operators for a more efficient grid operation in an uncertain environment [12].

Decision support tools. In a modern grid, decision support tools organize large data flows in real time from grid and equipment sensors to automate processes such as system restoration and grid power management. Decision support tools identify anomalies in large data flows that allow the system performance monitoring and compliance, as well as managing risk and resource adequacy in a utility system with variable resources and microgrids. The following decision support capabilities can be enabled in a modern grid:

1. Advanced tools and techniques in control centers that can improve the operator's situational awareness and decision making;

2. Simulation and modeling tools for off-line studies and real-time contingency analyses;

3. Energy Management System (EMS) tools that facilitate fast and real-time contingency analyses and allow grid operators to transfer real-time data to off-line simulation study tools and to transfer the simulation results back to the EMS environment for display and monitoring;

4. System restoration tools that help identify an optimal path from multiple restoration paths available following major blackouts;

5. Wide area tools that can interface with the realtime data across large geographical areas for replicating system events, and facilitating the timely investigation of major events for root causes, solutions, and what-if scenarios using EMS tools.

Bulk integration of renewable energy. The vision of grid modernization for integrating bulk renewable generation into the utility grid supports public policies to reduce greenhouse gas emission with detrimental environmental impacts, which are contributed by conventional fossil-fuel generation resources. $\mathrm{Nu}-$ merous technical issues are to be resolved, such as managing variable generation ramp rates, avoiding transmission congestion, and maintaining an adequate level of system protection, for integrating bulk renewable generation into existing utility systems. The flexibility can potentially originate from conventional generation 
and new sources such as controlled smart charging of electric vehicles, energy storage, and additional system coordination. Additional transmission infrastructure will be required to move the generated power from remote areas where renewable resources are concentrated to large load centers. Also, transmission systems must reduce the overall variability by aggregating and averaging variable generation over large geographic areas. Hence, power system planning must expand beyond traditional service territories to work regionally and inter-regionally. Capacity planning will need to cover not only maximum load scenarios, but also low and shoulder-load scenarios that may present higher reliability risks than before. It will also be necessary to increase the power system flexibility to respond to the variability of resources.

Integration of distributed energy resource. Such resources provide consumers with a number of benefits including increased electric system reliability, reduction of peak power requirements, provision of ancillary services (reactive power, power quality), reductions in land-use effects and rights-of-way acquisition costs, reduction in vulnerability to terrorism, and improvements in infrastructure resilience. Distributed energy resources tend to supplement, rather than replace, the primary generation resources employed by electric utilities. Widespread deployment of distributed energy resources requires modernization in grid design and resource integration technology, including smart inverters and adaptive protection and control systems. Today's electricity grid was not designed for the large integration of distributed energy resource technologies and Renewable Portfolio Standard policy goals in mind. Many of the distributed energy resources are variable in nature and, depending on their capacity size, operation characteristics, and the nature of the electric system to which they are connected, these resources need to be paired with energy storage technologies. This provision will improve control, accommodate fluctuation in output levels, and address fundamental changes in utility grid operations such as bidirectional power flow on radial distribution systems. Distributed renewable resources need to ensure effective management of feeder voltage maintenance and reverse power management.

\section{Aggregated energy storage for utility appli-} cations. Modern grids will typically employ larger sums of energy storage located on transmission and distribution systems and at consumer sites. Storage is unique because it can take energy from the grid, add energy to the grid, and supply a wide range of grid services on short (sub-second frequency) and long (hourly reserves) timescales. For instance, concentrating solar power paired with thermal storage becomes a dispatchable resource for grid operators. Energy storage technologies include: compressed air energy storage, pumped-hydro storage, lead-acid batteries, supercapacitors, sodium-sulfur batteries, zincbromine batteries, vanadium redox batteries, lithiumion batteries, flywheels, thermal storage, and hydrogen storage. Some storage technologies such as flywheels have fast response rates (seconds to minutes); other storage technologies, such as compressed air energy storage, are better suited to offer flexibility in the time frame of hours to days. Pumped-hydro storage is usable on a second to a day timescale.

Distribution system management. Distribution system management refers to the Smart Grid's ability to monitor, manage, and control distribution systems for specific applications. Automated distribution system devices have the promise of not only enabling Distribution System Operators (DSOs) to change the network topology, use local distributed resources for managing the grid (utilizing transactive energy for reducing operation costs, managing frequency and voltage) but also reducing the workload for field crews which use a two-way communication between the device and DSO to identify system anomalies remotely and momentarily. Distribution system management will require area-wide solutions and visualization with centralized modeling and operation. This critical area of grid modernization will give way to software-driven intelligence with central and distributed control systems for enhancing the utility grid reliability, resilience, and economics [13].

Consumer energy management tools. A modern grid will provide utility consumers with better information, choices, and control of their electricity services using the following approaches:

1. Value-added web tools will help consumers understand their energy usage on a historical basis, including trend analyses and benchmarking;

2. Authorized third-parties will gain access to and analyze consumer data, which can help consumers optimize their energy usage;

3. Consumers will be able to install Smart Grid devices that offer remote control capabilities via Web and automatically provide trade-off energy cost, comfort, and environmental impact based on user preferences;

4. Authorities will be able to use consumer access data to inform consumers of any emergency situations and guide consumers to find shelter points in the shortest possible time. 
Use of demand response. Demand Response (DR) involves the active management of consumer loads on a daily basis to balance the electricity supply and demand. DR, which will likely occur through automated load control, Smart Grid and smart metering, real-time pricing, time-of-use tariffs, and event based programs, can minimize the need to build costly new generation and delivery infrastructures. DR can be a cost-effective grid resource, though it requires strict regulations for response time, minimum magnitude, reliability, and verifiability of demand-side resources. The potential DR programs will tend to be optimized for operational value and targeted at specific consumer segments that are most able to respond to real-time events. Accordingly, fast communications for load management technologies are required in modern grids to help maximize DR convenience and cost-effectiveness.

Integration of electric transportation. The number of Plug-in Electric Vehicles (PEV) is expected to increase dramatically in the near future as the highdensity battery technology gets to be mature and additional battery charging stations are installed throughout communities. The present research examines the interaction utility grids, renewable energy sources, and PEVs, integrating energy management solutions and maximizing potential greenhouse gas reduction while smoothing the transition and reducing costs for $\mathrm{EV}$ owners. In the near term, modern utility grids must focus on deploying smart charging programs, including rates that require discrete measurement, such as timeof-use and demand-side management technique (e.g., PEV demand response). Smart charging programs will enable electric utilities to offer PEV consumers with cost saving and grid friendly methods of vehicle charging. In the longer term, with expected high levels of PEV penetration, electric utilities may have an opportunity to use PEVs for advanced smart charging techniques such as energy storage or vehicle-to-grid programs, which can ultimately support the integration of increased renewable resources into the modern grid.

Grid efficiency and voltage regulation. The scope of this area of grid modernization is to improve the power factor of distribution power flow, reduce distribution line losses, increase the utilization factor of grid assets, reduce the need for peaking generators, and enhance efficient operation of loads by reducing consumer consumption, thus contributing to overall peak demand reduction in power grids. In order to transform the distribution system data generated into actionable information that can be directly used by DSOs for grid modernization, data management and processing systems, as well as optimization algo- rithms, are required for utilizing Conservation Voltage Regulation (CVR) approaches and solutions that can enhance the efficiency of modern grids. The majority of CVR schemes contain two fundamental components: reactive power compensation and voltage optimization. Reactive power compensation is achieved through the operation of shunt capacitors in order to maintain the power factor at the substation transformer within a prescribed band. Voltage optimization is achieved through the operation of substation voltage regulators in order to regulate the voltage at specific end of points within a prescribed range. In this way, the peak load is reduced and the annual energy consumption is reduced.

Asset management and performance optimization. A modern utility grid will enhance the value derived from power grid assets through asset condition monitoring, leading to a faster and more comprehensive condition based maintenance evaluation. Asset condition monitoring will be enabled by the installation and use of various cost effective sensor technologies in power grids, which can collect real-time data relevant to the state of power system assets through an adaptive and relatively inexpensive and distributed communication infrastructure. The new set of embedded and automated field devices, such as smart transformers and communicating fault indicators among others, will integrate the monitoring and data collection capabilities of modern grids. Advanced data analytics functions such as tracking and monitoring algorithms, predictive analysis, and enhanced visualization tools will enable the transformation of field data into useful information to be used by modern grids in asset management and performance optimization processes.

Large power plants in modern electricity grids. Electric utilities are retiring a number of baseload coal and nuclear power plants, globally, which will affect transmission infrastructure planning and operation. The potential forecast for retirement in the United States is 50 gigawatts between 2013 and 2020. The factors driving such retirements include soft economy and declining growth in electricity demand, lower natural gas prices, and environmental regulations. Retirements are also affecting the nuclear power industry in the United States, with closures announced in 20122013 of five nuclear reactors, the first since 1998. Nuclear power supplied nearly $19 \%$ of U.S. electricity in 2013 (carbon free), which accounted for $10 \%$ of total installed capacity, with a record average of $90.9 \%$ capacity factor for the 100 nuclear units in the United States. The loss of these large plants could lead to a dramatic shift in power generation mix and modern grid implementation across the utility system across the globe. 
Increased use of natural gas for electric power generation. Abundant supply of natural gas with comparatively low prices has increased the interdependency of electricity and natural gas and affected electric power markets in the United States. Recent environmental regulations have further encouraged the electric power generation by natural gas and renewable energy units with lower greenhouse gas emission profiles. At the same time, dynamic systems in oil, gas, and alternative fuels infrastructures are increasingly monitored and controlled remotely through cyber networks that are powered by electricity. However, infrastructural changes may be needed to accommodate the future growth in natural gas use for power generation, including repurposing and reversals of existing pipelines, more looping and compression to the existing network, potential new pipelines, and additional processing plants and high-deliverability storage. The pumps and compressors along with natural gas gathering and transmission pipelines are often fueled with the natural gas flow through the station. When there are concerns about greenhouse gas emissions, there is even greater reliance on electric compressors. The increased reliance on electricity-powered compressors could increase the vulnerability of the gas transmission system to power outages. Centralized gas control stations monitor the flow of natural gas and collect, assimilate, and manage data received from compressor stations all along the pipeline. These control systems can integrate natural gas flow and measurement data with other accounting, billing, and contract systems. The data is transmitted through a privately owned or public communications network. The total loss of communications could result in manual operations of affected pipelines, which could be time consuming and at times detrimental to the system operation [14].

Electricity market signals for flexibility. Establishing short-term market products for flexible capacity in modern grids can incentivize available resources to respond to imbalances caused by variable resources over the minutes-to-hours time frame. In such market structures, demand response, demand-side resources, and storage devices could provide low-cost grid services, allowing more efficient grid operations and avoiding additional asset investments. Cost savings of the power system attributable to demand management and energy storage in modern grids can conceivably be much larger than the revenue market participants receive in current electricity market structures.

\section{Example of market signal for grid modernization}

Large errors in load forecasts may occur when high levels of renewable energy (e.g., 50\%) are integrated in electric power systems. Such errors may be caused by sudden unforeseen drops in renewable energy and late-day load pickups, which are coincident with reductions in solar photovoltaic generation as the sun sets. Accordingly, one option for reducing forecast errors is to utilize ramping reserves provided by conventional generators, which may leave the power system more vulnerable to equipment malfunctions. In such cases, the supply of ramping reserves may no longer leave such generators to compensate the grid for unforeseen contingencies. Another option is to utilize Synthetic Ramping Reserves (SRRs) provided by DERs and flexible loads in a distribution grid, which may offer significant cost advantages over conventional spinning or non-spinning ramping reserves. However, there is a considerable challenge for utilizing the flexible load option due to the fact that load responses will be required quickly. It is likely that DER or flexible load options would not sustain a useful response over any lengthy periods without disrupting customer services.

This section considers the use of Transactive Energy Provision (TEP) as an SRR option for aggregating and coordinating the dispatch of widely dispersed DERs in a utility system. TEP can offer SRR with desired ramp rate characteristics over the required time period. TEP represents an enabling technology that facilitates a large-scale coordinated rescheduling of netload for providing fast acting SRR services to a power grid. Figure 2 shows the TEP control algorithm in which the DSO integrates DR options for the power system operation and control. The DR options range from utilizing the onsite generation, energy storage system, and Conservation Voltage Regulation (CVR) to load shifting and load curtailment. The DSO utilizes an optimization model for the SRR procurement in which the key objective is the selection of optimal DR options based on the transactive energy control rather than applying the traditional command and control techniques. In Figure 2, TEP selections rely on energy market prices and the willingness of various DR providers to participate in power system operations. Here, the transactive energy applied to TEP refers to the use of optimization techniques by DSO for managing generation, consumption, and power flow using

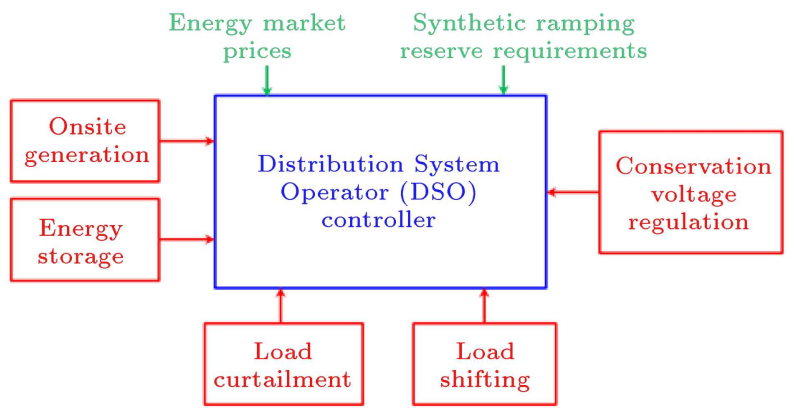

Figure 2. DSO Controller for implementing TEP. 
market based signals, which consider grid reliability constraints.

A typical transactive energy link has two signals: transactive incentive signal and transactive feedback signal. A transactive incentive signal represents the cost of energy delivered to a power system. This signal includes the existing cost and a forward projection cost. A transactive feedback signal represents the behavior of responsive power system elements.

Figure 3 demonstrates the TEP control mechanism for the DSO's optimal operation. In this figure, the incentive signal from the DSO to individual DR devices is a combinatorial pricing scheme, which is based on wholesale energy market prices. Individual DR devices in TEP will accordingly optimize their responses and provide DR capacities as transactive feedback signals to DSO. Collectively, TEP emulates the DSO's transactive energy provision for delivering SRRs. TEP provides predictable and consistent SRR quantities for extended hours without degrading end users' Quality of Service (QoS).

\section{Conclusions - A vision for grid modernization in the utility industry}

A modern grid can seamlessly promote greater reliability, resilience, security, and economics, while achieving better environmental performance, including reductions in greenhouse gas emissions. The traditional grid-where the electricity typically flows from central station power plants in one direction to consumers-is fundamentally different from a modern grid, where twoway power flows will be common on both long-distance high-voltage transmission lines and local distribution networks. To accomplish the task of modernizing the power grid, the grid will have to accommodate and rely on an increasingly wide mix of generation resources, including central station and distributed generation, energy storage, and flexible load. The modern grid should support a highly distributed architecture that integrates bulk and distributed system operations. The grid should also enable the operation of microgrids and aggregated controllable loads, which can operate in both integrated and island modes and range from

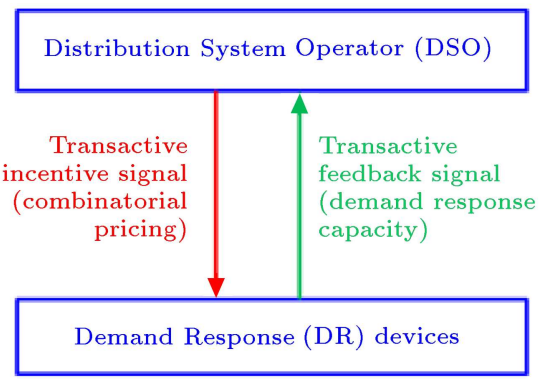

Figure 3. DSO's TEP Mechanism. individual buildings to multi-building industrial parks, hospitals, military bases, and academic institutions.

Grid modernization is an emerging concept that defines the utility grid as not just a physical structure, but one that encompasses a range of players. The modern grid will be an essential element in achieving the broad goals of promoting affordable, reliable, secure, resilient, and clean electricity and doing so in a manner that minimizes further human contributions to climate change. This new and broader concept of power grid architecture considers information systems, large industry participants, end-use retail consumers regulating agencies and market operators, communication and control networks, data management structures, and many other elements that exist outside the utility operations but interact with the grid operations. Grid modernization is shaped by public policies, business models, historical and cultural norms of practice, new technology derivatives, and socio-political factors.

It is clear that understanding the dynamics of power grid modernization and its transitions to better serve a modern society requires a clear appreciation for the use of innovation in managing the grid resilience, reliability, security, and economic objectives and their impacts on our daily lives. Will the transition to a modern grid be accompanied by larger changes in our societal behavior? Or will it ultimately be represented by a procedural change in how energy is produced and distributed? As to that, time will truly tell.

\section{References}

1. Shahidehpour, M., Yamin, H. and Li, Z., Market Operations in Electric Power Systems, John Wiley and Sons (March 2002).

2. Shahidehpour, M. and Wang, Y., Communication and Control of Electric Power Systems, John Wiley and Sons (June 2003).

3. Madrigal, M. and Uluski, R., Practical Guidance for Defining a Smart Grid Modernization Strategy, A World Bank Publication (2015).

4. Buchholz, B. and Styczynski, Z., Smart Grids - Fundamentals and Technologies in Electricity Networks, Springer-Verlag Berlin Heidelberg (2014).

5. Technical Report "The integrated grid", Electric Power Research Institute (2014).

6. Wu, L. and Shahidehpour, M. "Security-constrained unit commitment with uncertainties", Chapter in Power Grid Operation in a Market Environment: Economic Efficiency and Risk Mitigation, John Wiley and Sons (2016).

7. Shahidehpour, M. "Long-term electric and natural gas infrastructure requirements, national association of regulatory utility commissioners", http://www.naruc. 
org/Grants/Documents/ISPC\%20Long\%20Term\%20 Electric\%20and\%20Natural\%20Gas\%20Infrastructure \%20Requirements\%20WHITE\%20PAPER.pdf.

8. Haddadian, G., Khodayar, M. and Shahidehpour, M. "Accelerating the global adoption of electric vehicles barriers and drivers", Electricity Journal, 28(10), pp. 53-68 (Dec. 2015).

9. Investing in Grid Modernization, [Online]. Available: https://www.PerfectPowerInstitute.org (2010).

10. Warwick, W., A Primer on Electric Utilities, Deregulation, and Restructuring of U.S. Electricity Markets, Pacific Northwest National Laboratory (2002).

11. Technical Report "Grid modernization distribution system concept of operations", Sothern California Edison (2016).

12. Technical Report "Energy transmission, storage, and distribution infrastructure", US Department of Energy (2014).

13. World Economic Forum Report "Energy vision 2013 energy transitions: Past and future" (2013).

14. Haddadian, G. and Shahidehpour, M. "Ripple effects of shale gas boom in the united states-Shift in the balance of energy resources, technology deployment, climate policies, energy markets, geopolitics, and policy development", Elec. Journal, 22(2), pp. 1-22 (2015).

\section{Biographies}

Mohammad Shahidehpour is the Bodine Chair Professor and Director of the Robert W. Galvin Center for Electricity Innovation at Illinois Tech in Chicago. $\mathrm{He}$ is also a Research Professor at Sharif University of technology, King Abdulaziz in Saudi Arabia, and several universities in China. He was the recipient of the IEEE PES Outstanding Power Engineering Educator Award and the IEEE PES Douglas M. Staszesky Distribution Automation Award. Dr. Shahidehpour is a member of the US National Academy of Engineering, a Fellow of IEEE, and Fellow of the American Association for the Advancement of Science (AAAS).

Mahmud Fotuhi-Firuzabad received the BSc and MSc degrees in Electrical Engineering from Sharif University of Technology and Tehran University, Tehran, Iran, in 1986 and 1989, respectively, and the MSc and $\mathrm{PhD}$ degrees in Electrical Engineering from the University of Saskatchewan, Saskatoon, SK, Canada, in 1993 and 1997, respectively. He worked as a Postdoctoral Fellow in the Department of Electrical Engineering, University of Saskatchewan, from January 1998 to September 2001. He worked as an Assistant Professor in the same department from September 2001 to September 2002. Currently, he is a Professor and President of Sharif University of Technology. 